\title{
Virtual Communities of Police Service Support: \\ Providing SWOT Model in Line with the Order and Security
}

\author{
FaribaAzizzadeh, Islamic Azad University, Iran \\ Yosef Latifi, Islamic Azad University, Iran \\ Samira Azizzadeh, Bank of Dey, Iran
}

\begin{abstract}
Nowadays by formation of virtual communities, people support public services by sharing their own information and experiences. This article used the information of a Persian website in which the question and answer cycle takes place. In this research was used content validity. This research was utilized participant observation methods and descriptive statistics were used to analyze the data. Results suggest that people offer solutions for problems of each other regarding police services, order and security. They also transfer their knowledge without any benefit and only intrinsic motivation explains such behavior.
\end{abstract}

Keywords: Police service support, Virtual communities, Order and security 


\section{Introduction}

Life is increasingly become a mediated environment. Mediated social relationships offers important opportunities to enrich the human experience (Spagnolli et al., 2009). Intermediate technology offers unknown and strange forms of social interactions in virtual communities (Soukup, 2004). The virtual community is a new social phenomenon and the numbers of people who are members of these communities are increasing (Blanchard, 2004). The requirement for virtual communities is the existence of virtual space (Jones, 1997).

Internet with direct communication in cyberspace has provided new opportunities (Assaad\& Gomez, 2011) and has eagerly been with citizens through engaging. In the new era with the advent of information and communication technologies, the form of social networks has changed to virtual mode. These social networks have been madeon the Internet to get information about a variety of topics of public interest. Online social networks can provide information about the relationships between people (Gairin et al., 2012). In fact, this leads to the formation of new species from the interaction between people (Heydari and Kazemi, 1388) andleadscreation of electronic social networks. The emergence of social movements on the Internet is dynamic, appears and disappears without warning (Zimbra et al., 2010).

E-learning communities are environments in which professional and novices learn from each other, develop, and improve their skills. The members of the communities organize themselves as normal members, participating specialist or partners who support communitybased groups with common goals.Social learning and e-learning communities may have a great effect on learning to create and share knowledge (Baungaard\&Wangel, 2007). People in support groups can make very personal and intimate relationships with each other (those who are concerned about them and help them) (Green-Hamann et al., 2011)

One of the researchers pointed out that the Internet is a tool for communication and treasury of experiences, attitudes, behaviors, and the cause and people can have access to this reserve. A place where people want to share more time and information with others and make social networking media where borders, countries, cities and distance barriers are not an issue. According to the results of this research, people are interested in participating in these communities (Gozar, 2012). People create their stories, their values and goals, and ideas to share with others without having to speak directly with them (UmaschBers\& Chau, 2006). 
They can be like-minded with each other in spite of cultural or socio-demographics differences (Kim, 2011). In fact, social integration of the virtual network include: (1) establishment of the identity of the participating groups 2- building trust between themselves 3- sharing implicit and explicit knowledge (Bangaard Rasmussen \&Wangel, 2007)

One of the researches that was conducted in 2012 in Malaysia focused on the role of culture in knowledge sharing in social interaction based on social networking and the internet on line. The findings suggest that on line social network culture with the sharing of knowledge is associated with the way of life. The study was conducted on Malaysian Facebook consumers. Malaysian people are very careful about feelings of the other side and they tend to share everything about their interest. However, they are silent about many of the issues they feel which are personal or sensitive. The study showed that the subjects spend 1 to 4 hours per week time on Facebook. The people of Malaysia have used Facebook for the followings:

- Finding old friends

- Sharing knowledge

- Interacting with friends and family

- Meeting new people

- Commercial purposes(Chikh\&Berkani, 2010).

One of the other researches in this area suggests that more important positionsin the networkwill lead the person to have less accountability via e-mail (Kayam \& Hirsch, 2012). Butit should be considered that the relationship between a person's social status and reputation in the virtual network is very weak in virtual and professional communities (Lampel \& Bhalla, 2007).

Trust is one of the issues that have been discussed frequently in virtual communities (Elise Porter, 2012; Meijer et al., 2012). Trust has a prominent role in the process of virtual collaboration (Altschuller \& Benbunan-Fich, 2010). Trust is an important part of human interaction, plays an important role in increasing the information, and helps the users of social networks to collect reliable information (Meijer et al., 2012). In addition, trust among virtual teams will lead to success and achieve objectives (Elise Porter, 2004). Identifying and applying appropriate strategies of team leadership in the virtual environment, not only will increase the efficiency, but also positively affect the quality of trust and culture of virtual 
team members (Elise Porter, 2004). Studies show that virtual communities may experience a form of trust quickly, but this type of trust is very fragile and temporary (L. Jarvenpaa\& E. Leidner, 1998). In fact, trust can genuinely be createdamong the people in the virtual network (L. Jarvenpaa \& E. Leidner, 1998).

Security and public participation in its creation have taken another form with the formation of forums and virtual communities. In fact, these people are those who bring security together and membership in the virtual community does in this way. Citizensvariously participate in community safety (Anbari and Firuzjaeyan, 1388) that a new type relates to virtual space. Order and security need voluntary and independent association of citizens (Gavam and Dehganshad, 1389).

Virtual communities are defined as individuals and business partners gathered around common interests to interact with each other where interactions are driven through technology and some of the customs and norms (Elise Porter, 2004). Various issues are raised in thesenetworks and or employees of a specific organization, and so on. With the advent of the Internet and cyberspace, the physical form has changed to virtual communities. For virtual teams having a clear mission and goals are very important (C. Gluesing \& R. Riopelle, 2010). Web sites on the Internet related to particular communities that lead the formation of mutual funds can be found in abundance.Many people are trying to solve other problemsdue to common sense give their time to each other and without either material or immaterial benefit. The main research question is whether the support of order and security services through the formation of social networks will be good in order to its creation or not?

In the formation of a virtual community, security is one of the very important issues that is raised. Public participation in security is one of the best examples of participation in national development (Ambari and Firuzjaeyan, 1388), which has taken virtual flavor now with the formation of virtual networks. The aim of this study is to model the opportunities, challenges, strengths and weaknesses of social networks to support police services in order to create greater security and order. Also in this study, order and security situation of Kerman provinceis analyzedand how SWOT table can be used in order to establish order and security in the province. 


\section{Aim, Questions and Research Design}

According to studies, no research has been made in Iran on virtual communities of service and security order. To do this research, Google and Yahoo searching engines, websites, Persian FAQ were searched and finally Porseshkadeh sitewas chosen. One of the problems that existed in this search was that most sites were in Farsi, and were designed in which citizens ask the questions and government agencies respond to their questions. This site is a one-way flow of information.

At first people become a member on Porseshkadeh,then emerge their questions about the topics and answer to others' questions. The responses can be from certain source, or that the information and personal experiences of the respondents. Else from the richness or social place of the person and his physical and geographical limitations, people just through internet connection enter to these networks and consider their own questions or answer to others' questions. The main research question is whether the support of order and security services through the formation of social networks can be a good practice or not?

The following steps were to answer the above question:

1. Firstly, many Persian sites were searched and finally the site was selected. This site was selectedbecause of having the necessary features for social networks. People can have membership without restrictions and can ask or respond to questions posed by others without limitation.

2. Secondly, the questions raised by the members are reviewed and classified. At this point, questions about policing and security systems areseparated from other questions and the related details were classified.

3. In the third stage, the information related to mass questions about security and order are summarized, and finally they were analyzed.

One of the limitations posed in this research is that $93 \%$ of Internet users are the citizens of rich countries (Valinejad), and only $7 \%$ remains for the rest of the countries. Due to the limitations of the hardware and software of Internet in Iran, including low-speed access to the Internet and other constraints it was including among the few countries where the digital 
divide can be seen. The digital divide is the gap of knowledge created between rich and poor nations in terms of information (Valinejad). On one hand, it is predicted that knowledge will be acceptable only when itcould be converted information that can be analyzing and disseminating by computers. Social movements are able to provide information to mobilize and organize people around the world (Hatch and Kanliuf, 1389). In addition, the limitations of the hardware and software of Internet users in Iran have not leaded to the formation of citizens' networks with a common goal yet. However, the formation of these networks can be seen unbridled. It also further explore the issue of social networks and virtual markets, and common sense among members will be more visible. Despite the above limitations, virtual networks set up to solve problems.

Organizer of Porseshkadeh works through the sale of mobile phone charges and the award for selling more. It started its activities in early October 1388 Persian Calendarand at the time of this research; it has been 3 years since its launch. The site is in Persian and can have members without limits, purchase, take benefit of awards of much purchase and ask questions in the desired area or answer toothers' questions. Questionsabout religious sphere, computer, internet, marriage, counseling, medicine, geography etchave been considered and the questions related to the service order and security were extracted. Questions related to security and order was divided into 4 sub-categories that include judicial legal questions (which can be solved with the help of the police), military service, traffic law, order, and security.

In this study, questions extracted from the site for the order and the security services were classifiedin order to test the validity of the content. The questions were presented to the advisor and upon confirmation of the relationship between policing and order and security questions, they were re-classified and were more or less the same as classified by two person. In the next step,it is investigatedthat how many of these questions have been answered and are the answers concerning the plan? Is aparticular source used for responsesor only reflected in the experiences of individual respondents? A total 75 questions are extracted and analyzed. The research model is as follows: 


\section{Virtual Networks}

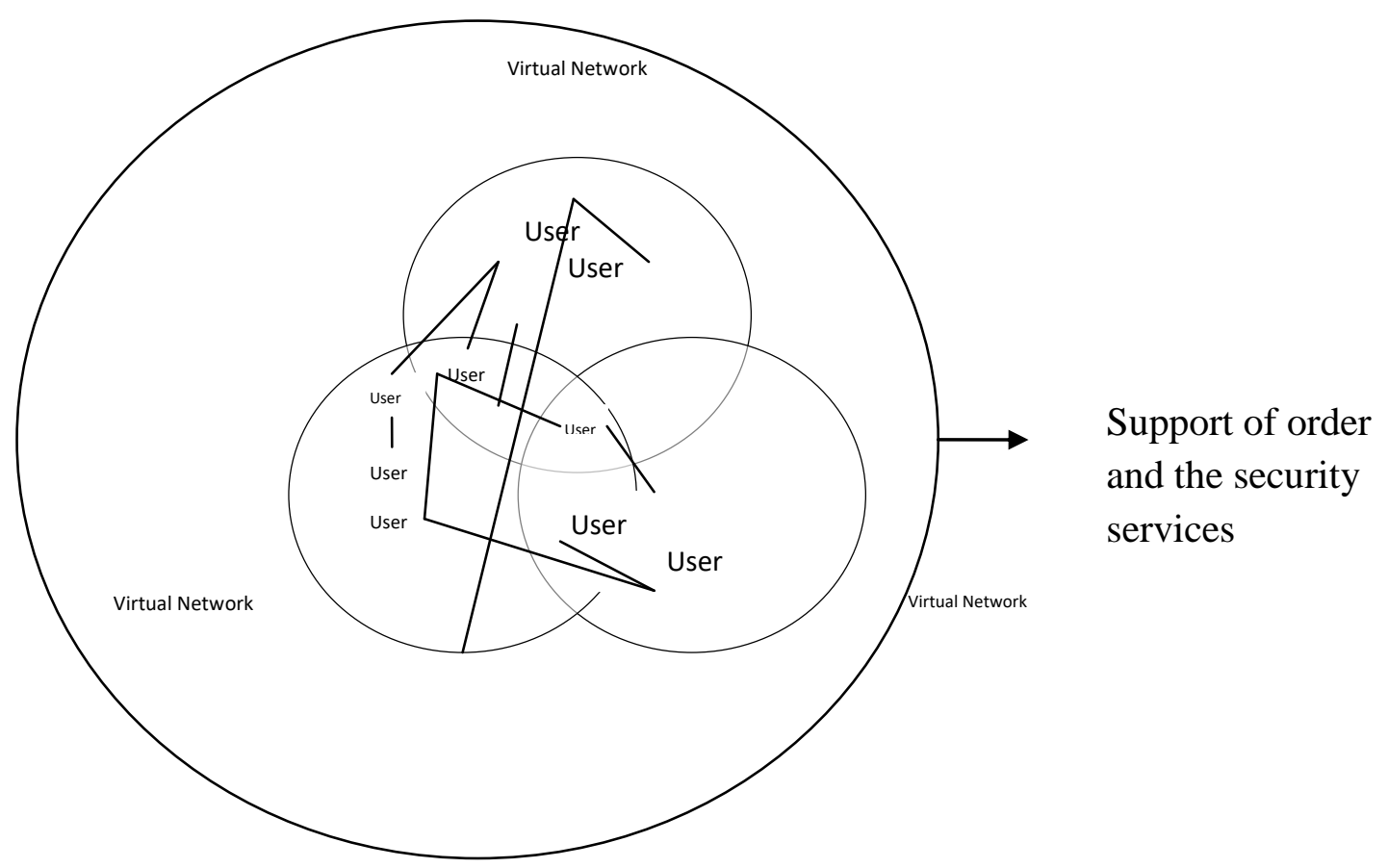

Figure1. Research model

Virtual network users can the police, citizen, public official and anyone else who has access to the Internet in the real world.

\section{Data Analyses}

The study shows that in total $48 \%$ of the questions were related to religious duties and problems have been proposed to the right of religious practices. The next category of questions was specific to tourism, Iran tour and city information that allocated $31 \%$ of the questions. Questions related to the solution of the questions included $16 \%$ and the rest of the categories, respectively, including cooking and housework (2\%), computers and the Internet $(1 \%)$, psychology, and marriage counseling $(0.6 \%)$, Humanities $(0.5 \%)$, and Science $(0.3 \%)$.

In total, $0.17 \%$ of the questions related to policing service and $18.6 \%$ of the questions remained unanswered. It shows that most of the asked questions have been answered. Peoplewere sensitive to others' questions and interested in them or although were not forced to answer, under internal interest tried to convey the experiences and knowledge and spent their time. Of theasked questions, 54.7\% related to traffic rules, $25.4 \%$ to order and security, $14.6 \%$ to judicial legal questions that can be solved with the help of law enforcement and 
$5.3 \%$ to the military system.Among the participants, most of the members have contributed only once (which contains $71 \%$ of the participants). While the citizens contributed only once,they are key members for new questions. It should be consideredthatone time contribution does not mean asking questions and a person may respond to another question and does not involve anymore. A few people who had active participation have answered $77 \%$ of questions. These people are known as the most knowledgeable users. $9 \%$ of respondents are among the most knowledgeable. These are key members of the site and those who have an active participation.

To check the quality of questions and answers related to the original question, aeration time for questions and answers and used resources were for the responses. In this context, it can be noted that $96.7 \%$ of the replies were related to the raised questions and were provided new information. Also, due to the need to type the responds, the responder spent the amount of time so that it reflects higher quality. Only $4 \%$ of the responses were with references and others were without reference to the source, and the experiences and personal information. The average time to respond to the posed questions was 4972 minutes. In fact, people for finding answers must wait an average of 82 hours. Table 1 shows examples of questions and answers of citizens.

\section{Question: How do I disable a STOLEN mobile phone?}

Hamedaskedon 31stFarvardin 1390 10:26 PM.

Answer: to check mobile serial number, press the following keys in sequence: $* \# 06 \#$ A digital code will appear on the screen. This number is unique to your handset. Write it down and keep it somewhere safe. When your phone is stolen, you can call your service provider and give them this code. Then they will be able to block your handset so even if the thief changes the SIM card, your phone will be useless. You probably will not get your phone back, but at least you know that whoever stole it cannot use it or sell it. If everybody does this, there would be no advantage in people stealing mobile phones.

Konjkavresponded on 31 Farvardin 1390 10:32 PM 
4. Question: what are the eligibilities for a passport for temporary exit from the country for subjected student?

Hadi-gin asked on 24 November 1390 11:39 AM

A: One way is to find aconference and get university agreements that you want to attend.Thenthey send anoutnumbered presentation to the Ministry of Science and you will get a sign, you would take other documents topolice +10 to havepassport, issued passport is for going to the same country the meeting took place just for a week before and after holding the conference. In addition you should pay 5 million Tomansto the conference Hamedresponded on 24 November 1390 11:57 AM.

5. Question: Automobile is minibus but is registered as truck for use on police site, to where it should be referred to reform?

Hamedasked on 8 August 1390 at 1:37 pm.

Answer: it should be applied to police department of traffic to be modified(in Tehran test settlements).

Konjkav answered on 8 August 1390, 5:11 am.

Table1: samples of questions and responses of citizens

\section{Conclusion}

Asthe study is conducted, the value of virtual communities in support of the service order and securitycan be realized. The study examined the following expectations:

Expectation1: virtual community members can meet each other problems in relation to the service order and security.

According to research, it is concluded that the members of the site (including the founders of the site and its users) have responded to the questions identified in this site that are related to security and order. In fact, members answered $81.4 \%$ of the questions. One can expect that people in the virtual network can reach answer of their questions about the security services 
and discipline. In addition, according to this study, it isconsidered that responses were related to the first questions $(96.7 \%)$ and provided new information.

Expectation2: virtual community members are interested in sharing expertise and information in connection with order and security services.

The study examined 43,311 questions and questions related to policing and order and security were among them. Only $4 \%$ of respondents had been with the source and $96 \%$ of the rest related to the information and experiences of citizens who were sympathetic to the questioner. This suggests that virtual community members are interested in sharing expertise and information to those who need to know it. In this transition, the respondents do not have any material or immaterial benefit. This showsthat people do this under the intrinsic motivation and spend their time to other members of the network.

Can the support of the police service and order and security through the formation of social networks in order to solve the problems of the community members do well? The results show that people respond to each other's problems in relation to policing and order and securityl and exchange theirown experiences and information in this field.

Dopeople respond to questions because they have common sense with questioner or are they interested in spending time on the Internet? Researches pointed out that both entertainment and looking for friends aremotivational factors in participation in these networks. Friendship, exchanging of information, social support and leisure are reasons for the participation of 399 members of 27virtual communities. Also information exchange (M. Ridings \&Gefen, 2004) and searching for information (Muhtaseb, R. Freg, 2008) have been identified as the most common reasons for people to join these virtual communities.However, this research led to the conclusion that answers are related to the question and individuals meet their internal motivation to answer.

Community members in the virtual network ask question or answer to others' questions (Azizzadeh et al., 2013), but the role of police and other security agencies remain steadfast because they provide services. These virtual communities just are as facilitator and show how to get support or awareness and their responsibility is to have the role of the police service 
and its related organizations. Of course, one of the issues that may occur with the development of virtual networks is the increment of corruption, because the members or people who can see it through these networks can be aware of the corruption channels and act through that. Of course, among the questions and answers relevant to this case we were not deal with it because it can be due to no extension of these networks (Valinejad). If the virtual network moves toward the spread of corruption in the process, it will give an opportunity for the police to follow the corruption.

Due to the low percentage of questions were related to the police service, order, and security, this site can be thoughtas a site to support services. In addition, due to limited access to the Internet, we cannot generalize the results to the total. Participants in the site are not representative of the whole of society, but they are those who are interested in asking or answering in virtual networks and the results show the behavior of these individuals. Fear of the destruction of the moral and lack of psychological security and the influx of malicious data through virtual space are logical reactions (Hatef, 1388).

Order and security in the range of public requires voluntary and independent citizens' communities (Gavam and Dehghanshad, 1389) and by the formation of virtual networks, forums will changefrom physical to virtual mode. It is necessary empower citizens to restore order and security and participate in the creation of order and securitythrough these virtual networks.Results show that in Kerman and surrounding villages there are somehow significant gender inequality (Ahmadi \& Garossi, 1383) and parents' awareness about the signs of drug abuse in this province is also at a low level (H. Rezaie and Mohammad Alizadeh, 1387). Also with a look at the crime, statisticsitcan be saidthat violent in the city of Kerman is in the upper limit. During the years of 1375 to 1381, the province ranked second with an average of 4.56 killings in the country and ranked first from 1376 to 1381 in collective quarrel (Sadigh Sarvestani, 1388). According to statistics, violent crime also increased significantly in the province (Arab Nejad and Yazdanpanah, 1390).

Kerman province is one of the most vulnerable regions in terms of order and security that enabled by expanding the virtual network and security people in order and can play the role of protector of the security in organs of law and order.The table below reviews the challenges, opportunities, strengths and weaknesses of virtual communities to support 
policing, order, and security which are conducted according to the results. The table below demonstrates the SWOT model to the virtual communities according to the results of this study and other studies.

(S)strengths

\begin{tabular}{|l|l|}
\hline - Inner motivation of citizens in asking and & - low number of questions in relation to \\
responding & security and order services \\
- less cost to build and lead this virtual & - lack of generalizability of the results \\
communities & $\begin{array}{l}\text { obtained from the website of the study to } \\
\text { the entire community }\end{array}$ \\
- supportingof police services and other & - absence of virtual community support for \\
security and help agencies to build order & policing and order and security \\
and security & - An increase in corruption \\
\hline - following of corruption canals & - lack of popular networks \\
- empowerment of individuals in order to \\
help order and security
\end{tabular}

Table 2. Identifying SWOT for virtual communities to support government services in order to establish order and security

Despite the above limitations, the virtual environment is conducive to the formation of social networks that address the problems inpeople relationship with police services and organizations associated with it. Internal motivation forms the behavior of members of the community. The study showed that these communitiescan support the role of policing and security systems. One way to make public participation space and acceptance of criticism (Khorshidvand, 1388) is to help spread of the virtual network exclusively toact toward the order and security. In this paper SWOT model was providedfor the formation of virtual networks to establish order and security. 


\section{References}

Ahmadi, H., Grousi, S. (2004) The effect ofsocial and culturalfactorsongender inequality in thefamilyofKermanandits surroundingvillages. MotaleateZanan, Vol.2, No.6, 5:30 Altschuller, Shoshana, \&Benbunan-Fich, Requel, (2010), Trust, Performance, and the Communication Process in Ad Hoc Decision-Making Virtual Teams, Journal of Computer-Mediated Communication, 16, pp. 27-47

Anbari, M., Firuzjaiyan, A. A. (2009)

Securitycooperativepartnershipexperiencesandbackgroundsof the peopleinvolvedin ensuringsecurity and order(with an emphasis on Iran). Journal oforder and securitypolice, Vol.2, No.2, 59:94

Arabnejad, F., Yazdanpanah, L. (2011) Factors associated withviolenceamongyouth35 to 18years in prisonanda history ofKerman. Journal ofSocial Welfare, Vol.11, No.43, $71: 95$

Assaad, Waad, \& Marx Gomez, Jorge, (2011), Social Network in marketing (Social Media Marketing) Opportunities and Risks, International journal of Managing Public Sector Information and Communication Technologies (IJMPICT), Vol. 2, No. 1, pp. 13-22 Azizzadeh, Fariba, Shirvani, Alireza, \&SarihiSfestani, Rasool (2013), Public Service Support Through the Virtual Social Networks, Management and Administrative Sciences Review, Vol. 2, No. 3, 293-303

Baungaard, Rasmussen Lauge, \&Wangel, Arne, (2007), Work in the virtual enterprisecreating identities, building trust, and sharing knowledge, AI \& Soc, 21: 184-199 Blanchard, Anita, (2004), Virtual Behavior Settings: An Application of Behavior Setting Theories to Virtual Communities, Journal of Computer-Mediated Communication, Vol. 9, No. 2

C. Gluesing, Julia, \& R. Riopelle, Kenneth, (2010), Correlating Survey Data and Network Data to Understand Performance in Global Virtual Teams, Procedia Social and Behavioral Sciences, 2, pp. 6551-6560

Chikh, Azeddine, \&Berkani, Lamia, (2010), Communities of practice of e-learning, an innovative learning space for e-learning actors, Procedia Social and Behavioral Sciences, 2, 5022-5027

Elise Porter, Constance, (2004), A Typology of virtual Communities: A Multi-Disciplinary Foundation for Future Research, Journal of Computer-Mediated Communication, Vol. 10, No. 1 
GairinSallan, Joaquin, Fernandez de Alava, Miren, \& Barrera-Corominas, Aleix, (2010), Review of knowledge creation and management processes through communities of practice in public administration, Procedia Social and Behavioral Sciences, 46, 21982204

Ghavam, A., Dehghan Shad, H. (2010) How to usecommunication patternsto restore orderandsecurity of citizens. Journal oforder and securitypolice, Vol.3, No.1, 1:16

Gozar, Hossein, (2010), A Literature on Challenges of Virtual Team's Leadership, Journal of Sociological Research, Vol. 3, No.2, 134-145

Green-Hamann, Sara, Campbell Eichhorn, Kristen, \& C. Sherblom John, (2011), An Exploration of Why People Participate in Second Life Support Groups, Journal of Computer-Mediated Communication, 16, pp. 465-491

Hatef, M. (2009) Challenges andprospects ofsecurityin cyberspace. Police Human DevelopmentJournal, Vol.6, No.22, 93:117

Heidari, F., Kazemi, M. (2009) E-democracy, the third generation of people involvement, Journal of Tadbir, N. 207, 38:43

Hossein Rezai, H., Mohammad Alizadeh, S. (2008) Middle and high schoolstudentsin Kermanparental awarenessabout thesigns ofdrug abuse. Journal of Olumpezeski University of Kerman, Vol.15, No.3, 261:268

Jo Hatch Mary, Cunliffe N.L., translated by DanaiiFard, H., (2010) Organization: Modern, Symbolic-Interpretive and Postmodern, KetabeMehraban publication, Vol. 1, p.p. 194, 301-302.

Jones, Quentin, (1997), Virtual-Communities, Virtual Settlement \& Cyber-Archaeology: A Theoretical Outline, Journal of Computer-Mediated Communication, Vol. 3, No. 3 Kayam, Orly, \& Hirsch Tijana, (2010), Using Social Media Networks to Conduct Questionnaire Based Research in Social Studies Case Study: Family Language Policy, Journal of Sociological Research, 2012, Vol. 3, N0. 2, 57:67

Khorshidvand, R. (2009) The Role ofthe participation ofnon-governmental organizations(NGO)in maintaining orderandsecurity. Police Human DevelopmentJournal, Vol.6, No.25, 35:44

Kim, Junghyun, (2011), Two Routes Leading to Conforming Intention in ComputerMediated Groups: Matching Versus Mismatching Virtual representations, Journal of Computer-Mediated Communication, 16, pp. 271-287 
L. Jarvenpaa, Sirkka, \& E. Leidner Dorothy, (1998), Communication and Trust in Global Virtual Teams, Journal of Computer-Mediated Communication, Vol. 3, No. 4 Lampel, Joseph, \&Bhalla Ajay, (2007), The role of Status Seeking in Online Communities: Giving the Gift of Experience, Journal of Computer-Mediated Communication, 12, pp. $434-455$

M. Ridings, Catherine, \&Gefen David, (2004), Virtual Community Attraction: Why People Hang Out Online, Journal of Computer-Mediated Communication, Vol. 10, No. 1 Meijer, Albert, Grimmelikhuijsen, Stephan, \& Jan Brandsma Gijs, (2010), Communities of Public Service Support; Citizens engage in social learning peer-to-peer networks, Government Information Quarterly, 29, 21-29

Muhtaseb, Ahlam, \& R. Freg, Lawrence, (2008), Arab Americans' Motives for Using the Internet as a Functional Media Alternative and their Perceptions of U.S public Opinion, Journal of Computer-Mediated Communication, 13, pp. 618-657

SeddighServestani, R. (2009) Social pathologysociology ofdeviance. Tehran, SAMT Publications

Soukup, Charles, (2004), Multimedia Performance in a Computer-Mediated Communication as a Virtual Drama, Journal of Computer-Mediated Communication, Vol. 9, No. 4

Spagnolli, Anna, Lombard, Matthew, \&Gamberini, Luciano, (2009), Mediated presence: virtual reality, mixed environments and social networks, virtual reality, 13, pp. 137139

UmaschiBers, Marina, \& Chau, Clement, (2006), Fostering Civic Engagement by Building a Virtual City, Journal of Computer-Mediated Communication, 11, pp. 748-770 Valinejad, M., Digital Gap, the Challenge of Transition from Industrial Society to Information Society, Journal of Bank \& Economic, N. 52, 17:25

Zimbra D, Abbasi A, \& Chen H, (2010), A Cyber-archaeology Approach to Social Movement Research: Framework and Case Study, Journal of Computer-Mediated Communication, 16, pp. $48-70$ 